\title{
Psychology in a New Tempo: Instances and Consequences of a Cult of Celerity
}

\author{
Janet Landman
}

The University of Michigan

\begin{abstract}
This article presents a critique of psychological, disciplinary, and cultural propensities to favor speed of thought and action over other considerations, a propensity which warrants the designation "cult of celerity." Certain cultural manifestations of a cult of celerity are briefly discussed. A number of areas of illustrative psychological inquiry are examined-heuristics, the satisficing principle, the role of haste in social behavior - each of which documents the occurrence and the costs of velocity in human thought and behavior. In addition, it is suggested that psychological theory may itself be in danger of succumbing to a cult of celerity. Finally, implications of the cult of celerity for psychology as a discipline and for advanced culture are explored.
\end{abstract}

The message "Sorry, this will take some time" appears in emerald hues on my computer screen at a point in the program when the pace of the processing is less than instantaneous. Despite the apparent innocence of this dispatch about dispatch, I find the apology somewhat disturbing. To me the message reveals a concern with celerity that can and at times does amount to an obsession.

By 1983 when Time magazine proclaimed the computer the Person of the Year, a cognitive revolution had already taken place in psychology and related disciplines, one of the chief features of which is the installation of the computer metaphor as a reigning metaphor for the mind-indeed, for the self. The computer metaphor for the mind has not remained confined within the boundaries of academe, but has made its way into popular culture through books such as Dennett's (1978) Brainstorms, Hofstadter's (1979) Godel, Escher, Bach, Papert's (1980) Mindstorms: Children, Computers and Powerful Ideas, and Turkle's (1984) The Second Self: Computers and the Human Spirit. In the face of these concurrent cultural and disciplinary developments, it would seem to be no overstatement to speak of a culture-wide computer para$\operatorname{digm}($ Kuhn, 1970) - that is, a set of models, beliefs, and values shared by a community, in this case, models, beliefs, and values shared not only by a community of scholars but by much of developed culture.

Earlier versions of this manuscript benefited from thoughtful reading and response by Hazel Markus, George Rosenwald, and two anonymous reviewers.

Requests for reprints should be sent to Janet Landman, The University of Michigan, Department of Psychology, 580 Union Drive, Ann Arbor, MI 48109. 
It is understandable that the computer might serve as a powerful model; as Sherry Turkle asserts in The Second Self: Computers and the Human Spirit (1984), "the computer is enough like a mind to make analogies between the self and programs seem plausible" (p. 161). Perhaps it bears repeating that models and metaphors are more than linguistic frills. Employing apt metaphors to make this point, Kenny $(1979, p .5)$ describes the set of causal statements as the skeleton of a theory, while the heart of a theory is a metaphor. In a similar vein, Marcuse (1964) once asserted, "We are possessed by our images, suffer our own images" (p. 250). A powerful metaphor is a constitutive force. The high-speed computer image which dominates much of current psychology, as well as much of cybernetic culture, is one of these powerful constitutive forces. Already a number of cybernetic characteristics have made their way into cognitive models of the mind and of the self (e.g., limited capacity, serial processing, hierarchical organization of information). This article is focused specifically on a cybernetic characteristic which, though always present as a given, has heretofore largely escaped analysis as a power in its own right - speed.

In this cybernetic age it is only a slight exaggeration to speak of a "cult of speed" - an over-valuation, indeed, a near-deification, of speed. Of course, the computer revolution has not caused the cult of speed; the causes are elsewhere (Bell, 1980; Horkheimer, 1941/1978; Reich, 1983). Nevertheless, insofar as we think of ourselves as like a computer, the cybernetic revolution contributes to a certain obsession with celerity.

Speed, of course, is not inherently a bad thing. And speed's city cousin, efficiency, is in many ways a very good thing. Whenever time spent in drudgery can be reduced in favor of time spent in more interesting, more worthy, or simply more enjoyable activities, that is all to the good. Indeed, a concern with speed and efficiency seems to be a luxury which those in developed countries can afford precisely because they have succeeded in eliminating much of the plodding toil of life, through the development of high technology (Linder, 1970). Time is valuable, if only because people are mortal.

Inasmuch as the cybernetic revolution is both irreversible and at least a partial blessing, the intent of this analysis is not to attempt to slow down or abolish the development of computer technology in the public sector or the computer paradigm in the scientific sector. These are without question good ideas. But as Langer (1942) pointed out in Philosophy in a New Key, "the best ideas are also those most worth reflecting on" (p. 39). Accordingly, the purpose of this analysis is to subject to critical reflection the following matters: (1) some of the human and socictal costs exacted by certain instances of the cultural preoccupation with celerity; (2) certain human tendencies to celerity of thought and action revealed by psychological research; (3) certain signs that psychology itself-specifically, the canons by which psychological theory is evaluated - may be succumbing to something of a cult of celerity. More broadly, it is the thesis of this article that the image of the mind as high-speed computer is one that we suffer from, insofar as it directs us to think of ourselves in ways that militate against the beneficent development of the individual and society.

First, however, some conceptual distinctions need to be drawn. Speed refers to rate of execution or rate of movement; in its technical sense velocity adds the dimension of direction to the magnitude of motion. For the present purposes, specd and 
velocity will be used interchangeably, reflecting the assumption that most or all of human activity is directed. The thermodynamic concept of efficiency will be extended to the psychological and social realms, resulting in a definition of efficiency as the ratio of energy output to energy input. For the most part, this critique is directed at speed rather than efficiency, although, because of its close relationship with speed, the latter concept cannot entirely escape critique.

\section{INSTANCES AND COSTS OF A CULT OF CELERITY AS MANIFEST IN MODERN CULTURE}

Speed exacts a number of human costs: costs in the quality of social interaction, individual development, and intellectual activity. This portion of the critique briefly discusses these three manifestations of a cult of celerity in the culture at large.

In The Phantom Tollbooth (Juster, 1961) there is a cautionary tale which illustrates in a fanciful way one of the social consequences of an infatuation with speed. The story takes place in the location where an attractive city, called "Reality," had once existed. In the following passage, Alec Bings is telling Milo, the child protagonist of this book, about the once-glorious city called "Reality":

Many years ago, on this very spot, there was a beautiful city of fine houses and inviting spaces, and no one who lived here was ever in a hurry. The streets were full of wonderful things to see and the people would often stop to look at them. "Didn't they have any place to go?" asked Milo. "To be sure," continued Alec; "but, as you know, the most important reason for going from one place to another is to see what's in between, and they took great pleasure in doing just that. Then one day someone discovered that if you walked as fast as possible and looked at nothing but your shoes you would arrive at your destination much more quickly. Soon everyone was doing it. . . No one paid any attention to how things looked, and as they moved faster and faster everything grew uglier and dirtier, and as everything grew uglier and dirtier they moved faster and faster, and at last a very strange thing began to happen. Because nobody cared, the city slowly began to disappear. Day by day the buildings grew fainter and fainter, and the streets faded away, until at last it was entirely invisible. There was nothing to see at all. (pp. 117-118)

In this tale, that which ceases to be apprehended ceases to exist. Something like this can occur on the psychological level as well-unseen or unloved people may begin to doubt their own value and perhaps even their own existence. At the societal level, insofar as individuals fail to take the time to behold one another appreciatively, to that extent the social world is less beautiful, less pleasurable, indeed, less real.

To leave the fictional world for the real world of today, it is instructive to note that Silicon Valley has been described (Moody, 1984a) as a place where "Daddy moves Little Sister into Big Sister's room so he can use the space to invent video games" (p. A15). Of course, the erosion of human connectedness is neither caused by nor limited to Silicon Valley. For the rest of us, bookstores bulge with volumes advising us how to avoid wasting time: The One-Minute Manager (Blanchard \& Johnson) which came out in 1981 was quickly followed by The One-Minute Father (Johnson, 1983a) and, inevitably, The One-Minute Mother (Johnson, 1983b). But regardless of the causes of cybernetic haste, the erosion of interpersonal relationships may 
be a particularly troublesome problem in a culture obsessed with headlong progress - a culture where many people rush full-tilt from one task to another, thinking of others as either aids or impediments to progress.

In a culture which deifies speed, the depth and breadth of individual development will likely receive short shrift, as well. Nietzsche's (1874/1964) warning regarding the pernicious consequences of an excessive concern with the past applies to a culture excessively concerned with speed: a cult of celerity has the potential to "crush [youth's] desire for a slow ripening by the contrary desire to be soon productive, ready, and useful" (p. 88). The following portrait of Craig W., a law student speaking to incoming freshpersons at the University of Michigan "Meeting the big U.," 1981) describes a young man whose way of life epitomizes the cultural obsession with speed, and the desire to be "soon productive, ready, and useful":

Next on the agenda was a meeting in the Union's Anderson Room conducted by Chris and her orientation partner, Craig W. Craig, an overly self-possessed law student in khaki shorts, Hawaiian shirt, and a Boston Red Sox cap, did most of the talking. Apart from telling us where to buy books and not to get too depressed if we didn't end up top of our class, Craig told us he ran his own business, dated, took part in fraternity activities, was a big honcho at UAC (controlling a disbursement of $\$ 70,000$ ), and could show us ways to save time we never knew we had. "I'm the busiest person I know," said Craig, and nobody said otherwise. (p. 10)

In a world overly concerned with instant results, it will be difficult, not only for Craig W., but for most of us, to entertain the idea that the process of developing one's individuality or character may be a singularly low-tech enterprise which can be harmed by an obsession with breathless progress (Mill, 1859/1952).

One might suppose that, although the cult of celerity is admittedly hard on interpersonal relationships and on individual development, it at least has the virtuc of improving the quality of one's work. Unfortunately, this is not necessarily the case. Psychological research continues to document the intuition that the quality of work also suffers from the cult of speed (c.g., Andrews \& Farris, 1976; Luchins, 1942; Yukl, Malone, Hayslip, \& Pamin, 1976). For example, recently reported studies (Kelly \& McGrath, 1985; McGrath, Kclly, \& Machatkd, 1984) show that time pressure reduces the length, originality, quality of presentation, and creativity of group products and solutions.

I can hear the protests now. "That is all well and good, but are we really to interpret such findings as a mandate to slow down on the job? You tell my boss." And "It may be possible for some people to slow the pace of their work, but in my fastpaced line of work the operational principle is "He who hesitates is lost." Granted that objections like these often have considerable validity, it would not hurt to consider the work of geneticist Barbara McClintock as a case in point illustrating the value of a low-tech, slow-track approach-even in a high-tech, fast-track line of work.

McClintock has all her life studied maize, a plant that has at least one unfortunate characteristic with respect to the expeditious execution of research: it reproduces at the saturnine rate of once a year. In contrast, the speedy fruit fly produces a new generation every two weeks. And bacteria reproduce with truly impressive dispatch - every twenty minutes. While her contemporaries concentrated on bacteria and Drosophila, McClintock studied maize. According to Fox Keller 
(1983), McClintock's biographer, biology's preference for organisms that produce quick results was partially responsible for its failure to recognize the originality and importance of McClintock's discoveries for some thirty years; McClintock's colleagues were no longer conversant with the vocabulary used to describe genetic phenomena in more slowly replicating organisms such as maize, a vocabulary that was McClintock's lingua franca. Happily, the paradigm-altering contributions of McClintock were eventually recognized by her colleagues, as by the world, when in the 1980s she was awarded a Nobel prize for her discovery of transposable genes in maize.

What can we learn from McClintock's example? When McClintock speaks to younger scientists, she advises them to take their work more slowly - "to take the time and look" - at their organism. Fox Keller (1983) describes such a meeting between McClintock and graduate students in the biology department at Harvard. Fox Keller (1983) reports that these students listened to McClintock's message with both respect and skepticism:

they were . . troubled. Where does one get the time to look and think? They argued that the new technology of molecular biology is self-propelling. It doesn't leave time. There's always the next experiment. . . The pace of current research seems to preclude such a contemplative stance. McClintock was sympathetic, but reminded them, as they talked, of the "hidden complexity" that continues to lurk in the most straightforward-seeming systems. She herself had been fortunate; she has worked with a slow technology, a slow organism. (p. 206)

I suspect that not only molecular biologists, but all of us, understand too well the skepticism of these students. The very real exigencies of the marketplace do militate against the use of slow technologies, difficult research organisms, delayed publication or production. More generally, in technologically advanced cultures, where time is money, speed and efficiency can come to be uncritically celebrated, despite their sometimes malignant impact on individual, interpersonal, and work life.

Signs of a cult of celerity appear not only through social analysis, but also in empirical analysis; in particular, psychology has documented a number of examples of a cult of celerity, as well as some of the cognitive and social costs of these.

\section{INSTANCES AND COSTS OF CELERITY AS IDENTIFIED BY PSYCHOLOGICAL INQUIRY}

Recently, psychology has undergone a major shift of worldview that is commonly referred to as the "cognitive revolution," so called because it has seemingly overturned both the behavioral and the psychodynamic empires that immediately preceded it. Whether or not the cognitive revolution is truly a revolution, in Kuhn's (1970) sense of a tradition-shattering shift to a single paradigm shared by virtually all members of a scientific community, the cognitive approach is indisputably a ubiquitous and potent force to be reckoned with in psychology and in other social sciences. According to Mandler (1981), "if one surveys theory and practice in psychology today, the conclusion is that cognitive psychology is mainstream psy- 
chology" (p. 14). A recent review of the history of mental metaphors in psychology comes to the same conclusion (Gentner \& Grudin, 1985).

The heart of the cognitive revolution is an information-processing metaphor of the mind, whereby the mind is not atypically portrayed graphically via a flow-chartlike system of interconnected boxes and arrows, with the boxes bearing labels (Anderson \& Bower, 1973) such as "Input," "Perceptual Parser," "Memory," "Executive," "Visual Buffer," "Language Generator," and "Output" (p. 137). As these labels suggest, in information-processing terms the mind is conceived as something very like a thinking machine, a computer, one of whose chief functions is to take in and to process information from the environment-and to do so expeditiously.

Furthermore, it is assumed by some cognitive psychologists and by most of those who call themselves cognitive scientists, that a simulable theory-one capable of implementation via a computer program - is in principle preferable to a nonsimulable theory. In the strong version of this assumption, programs are theories, and theories must be programs (Winston, 1977, p. 258). Herbert Simon, a notable proponent of the strong version of the simulability assumption, enthusiastically predicted in 1957 that "within ten years programs would be the standard form for psychological theory" (cited in Turkle, 1984, p. 244). Perhaps because thirty years later, this forecast has not been realized, the more common stance toward simulability is now a more moderate one. In the weaker version of this assumption, programs are "simulations of models which approximate to theories" (Thagard, 1982 , p. 155), which in turn presumably approximate to reality - that is, to the mind. In any case, cognitive theory has as a more or less strict goal the simulability of mental functioning.

The human being that is made in the image of the cognitive paradigm is more or less a high-speed thinking machine. How information is processed by the thinking machine is the questions of the age; and answers to this question are now emerging at a rapid rate. The following section describes three areas of psychological inquiry that document certain proclivities toward and penalties of velocityheuristics, satisficing, and a set of social psychological phenomena which highlight the role of haste in human behavior.

\section{Hasty Cognitive Processing Via Heuristics}

Heuristics are short-cut principles or rules of thumb thought to be utilized when making decisions, solving problems, estimating probabilities, and making other types of mental judgments. Amos Tversky and Daniel Kahneman are the authors of an influential series of investigations of a variety of heuristics, including the representativeness heuristic, the availability heuristic, and the simulation heuristic.

According to Kahneman and Tversky (1973), the representativeness heuristic is a short-cut cognitive strategy often brought to bear when people are attempting to determine probabilities or causation. For example, someone asked to determine the likelihood of a specific individual's belonging to a particular occupational group (e.g., lawyers versus engineers) might base this judgment on a quick comparison of the target individual with certain stereotypical features of the groups in question. Thus, if the target individual were described as an introverted person with a hobby of working mathematical puzzles (characteristics seemingly more representative of engineers than of lawyers as a group), he or she would be judged as belonging to the group of engineers, regardless of other, more pertinent consider- 
ations such as the statistical incidence of engineers versus lawyers in the particular population.

Similarly, according to the availability heuristic, people tend to judge the frequency of certain events by the ease with which specific instances are brought to mind (Tversky \& Kahneman, 1973). For example, individuals might estimate the incidence of cancer deaths in dogs by using cognitive availability as a rule of thumb, so that someone who easily brings to mind several examples of cancer deaths in the dogs of friends and relatives might then surmise that cancer is a major cause of death in dogs. A high-tech example of the availability heuristic appears in this description of a parking lot in California: "Look at a parking lot in Palo Alto, and you'd think Mercedes-Benz made more cars than Chevrolet" (Moody, 1984b, p. A16).

Finally, the simulation heuristic is a cognitive short-cut by which people are thought to construct and to "run mental models in an effort to deal with actual life events, to imagine alternative outcomes, to predict future events, or to assess causation" (Kahneman \& Tversky, 1982a, 1982b). The following are among the research questions which have been addressed concerning the cognitive content and the emotional consequences (e.g., regret) of using the simulation heuristic: (1) Given the same unfortunate outcome, do people experience more regret for having attained the outcome via action rather than inaction? (2) Given the same unfortunate outcome, do people experience more regret for "near misses" than for "misses by a mile"? (3) In the face of an unfortunate life event, are people more likely to imagine undoing the unusual than the usual antecedent events? Experimental vignette studies have yielded affirmative answers to each of these questions (Johnson, 1986; Kahneman \& Tversky, 1982a, 1982b; Landman, 1984; Landman, in press).

According to Kahneman and Tversky (1982a) each of these findings can be accounted for in terms of the relative ease of simulation of the alternatives. For example, the greater regret for near-misses than for decisive misses is due to the greater ease with which the alternative possibility (a "hit") is simulated; likewise, the greater regret for action than for inaction is due to the greater ease with which the alternative possibility (inaction) is simulated. In addition to the unmistakable equation of mind and computer built into the very concept of simulation heuristic, efficiency is also an integral characteristic of the hypothesized mechanism of thought.

As these illustrations suggest, heuristics have the advantage of simplifying complex cognitive tasks. At the same time heuristics have the disadvantage of promoting erroneous judgments, because the most representative, the most available, and the most readily simulated instances are not always the most informative. Psychology has been well aware of the liabilities of heuristics. The speed/accuracy trade-off is among the more active areas of research in cognitive psychology. Indeed, the business of identifying and describing various heuristics has often included explicit exhortation against their overuse or erroneous use. At the same time, the ultimate value of speed of thought - if only we could have both speed and accuracy - goes largely unquestioned in psychological theory, as it does in the culture.

\section{Hasty Decision Making Via Satisficing}

Until recently, one of the most highly credited economic theories of decision making was the theory that, when making decisions, the rational person seeks complete knowledge of alternatives in order to make decisions which maximize pleasure or 
profit. Recently this model has been replaced by one in which economy of effort supersedes thoroughness of effort. According to Simon's (1969) Nobel-prize-winning theory of decision making, people in the throes of a decision do not consider all possible alternatives but search only until they hit upon an option which appears satisfactory.

To draw upon Simon's own example, let us consider the decision problem of the traveling salesperson who wishes to cover 40 towns most efficiently - that is, with the least mileage. A solution to this problem can be attained using the factorial algorithm, which prescribes the following two-step problem-solving procedure: (1) calculating the mileage for all possible routes and (2) choosing the shortest of these routes. However, the time and effort required just to map out all possible routes is prodigious, since the total number of all possible routes through 40 towns is 40 factorial, or 8.15915 times $10^{47}$.

Simon argues that, faced with this enormously time-consuming task, it is more sensible to employ a good heuristic rather than the full algorithm - that is, to use a short-cut strategy which is likely to produce a short-enough route without exhaustive search. In this theory the heroic principle of maximizing is whittled down to the realistic principle of satisficing. ' But, just as with heuristics, a practical problem with the satisficing principle is that the more hastily chosen strategy may not be the best one.

More importantly, notwithstanding the fact that there are times when speed is preferable to accuracy (when, for example, it is more important to do something than to do the very best thing), given the power of the cybernetic model of the mind and the current cybernetic ethos, satisficing may too easily be transformed from a description to a prescription.

\section{Hurried Thought and Action in the Social Domain}

Social psychology has identified a number of other ways in which human beings tend to honor hurry at the expense of other values. Much of social psychological research has made the point that we tend to "jump to conclusions" about other people based on little or no information. Sex, race, name, physical attractiveness, seating position at a table, amount of light on the face - all these are examples of pieces of information or circumstances which have been found to unduly influence people's causal attributions, opinions, and impressions of others (Taylor \& Fiske, 1978).

Not only do we make haste to draw important social inferences based on little or no good evidence, we also behave in a manner which reveals the premium we often place on hurry. Kansas undergraduates (Batson et al., 1978) and Princeton seminary students (Darley \& Batson, 1973) alike were found to respond differently to a groaning man depending on whether these students were in a hurry to get somewhere or not. Those who were induced to feel in a hurry were far less likely to stop and help a distressed person than those who were put under no time pressure.

\footnotetext{
${ }^{1}$ A similar phenomenon, the sufficiency principle, has been identified by attribution researchers in social psychology (Jones \& Davis, 1965). It scems that we frequently scttle for an adequate explanation - e.g., a single, plausible cause - of a social cvent, rather than cxhaustively searching for alternative or multiply determining causes.
} 
Taken together, these examples describe a mental world in which fleetness of thought is favored over perspicacity of thought and a social world in which velocity is favored over virtue. Despite the fact that precipitate thought and action is often deficient thought and action-deficient in accuracy, fairness, or social responsibility-precipitate thought and action are often the order of the day. Psychology does well to unveil these seemingly inherent preferences for speed. But insofar as one's culture holds tenaciously to the value of speed of thought and action, it seems likely that such natural inclinations - and their associated errors - will be magnified rather than curtailed. Indeed, in a culture which reduces thinking to an "energy-conserving operation" (Horkheimer, 1941/1978, p. 28), the wisdom of more economical models of thought and behavior seems almost beyond challenge. As a consequence, such cultural norms may find their way into the theory and practice of science. Indeed, there are indications that psychology may find itself being subverted by the fast-track ethos of the cybernetic age, a prophecy made by Bell (1973) over a decade ago with respect to science in general.

\section{THE CULT OF CELERITY IN PSYCHOLOGICAL THEORY}

Psychology's own flirtation with the cult of celerity can be seen in a number of instances. Perhaps most salient to the researcher is the renewed popularity of reaction time as a methodological feature of a wide range of investigations. In addition, the proliferation of quick-access, modularized cognitive structures (schemas, scripts, prototypes, for example) as subjects of theoretical and empirical endeavor is striking. Still, so far, psychology ${ }^{2}$ has honored velocity not so much as a major deity, but as a household god, much of whose glory derives from its association with the information-processing model of the mind. However, there is some real possibility of psychology's elevating speed to a position of greater eminence, by embracing speed as a criterion by which to assess its own theories.

Along with the traditional canons long used to evaluate theory-e.g., precision, parsimony, generality - some psychological scholars have proposed the criterion of efficiency. It has been recommended that when confronted with competing plausible theories of mental functioning (for example, the theories that ideas are encoded in propositional versus in imaginal form), one should prefer the more efficient theory over the less efficient one (Anderson, 1978): "a constraint on any theory is that it not propose that the system is processing information inefficiently" (p. 273). In this formulation, what is meant by efficiency is speed of processing - for example, time required to proceed from the perceptual to the inferential phases of information processing - as measured by the relative rates of processing observed via computer simulations of the competing theories. The usefulness of the efficiency criterion, it should be noted, depends upon another previously mentioned standard by which cognitive theories are judged-simulability-because theories which have been

\footnotetext{
${ }^{2}$ For the present purposes, I am excluding from consideration the practicing branches of psychology, notably clinical psychology, and am instead referring to the research-generating areas of psychology - for example, experimental, social, personality, developmental psychology. Within these domains, I am focusing particularly on the first two, the experimental and social areas, because (1) these are areas with which I am on familiar terms and (2) they have embraced the computer paradigm and have documented the occurrence and deleterious consequences of an over-valuation of velocity earlier and more comprehensively than other sub-disciplines within psychology.
} 
implemented as computer programs are most readily susceptible to evaluation by the criterion of efficiency.

Of course, efficiency does not have the power to veto a good theory merely on the basis of this single criterion. This standard comes into play given competing theories that are equivalent in other dimensions. In addition, there is currently nothing like a consensus within psychology about the validity of efficiency - or simulability - as standards by which to assess psychological theory. However, efficiency does reflect a strong value commitment shared by many in the psychological community. Moreover, given the wholesale exportation of other concepts, principles, and methods from cognitive science into the various sub-disciplines of psychology, there is ample reason to take these ideas seriously. But to accept the criterion of efficiency would be to enshrine rapidity of mental processing, something which we may not want to enshrine just yet.

For the criterion of efficiency more specifically and the cult of celerity more generally rest upon at least two arguable assumptions - the simulability assumption and the utilitarian assumption. I have already alluded to the simulability assumption and its role in supporting the standard of velocity. But the inadequacy of the computer program as a metaphor for the human mind has been cogently argued by others (e.g., Dreyfus, 1979; Searle, 1982; Turkle, 1984; Weizenbaum, 1979). Not only does the computer analogy fail to take account of the mind's biological "wetware" and its emotional functioning, but it also fails to accomplish true comprehension: "as far as the computer is concerned the symbols don't symbolize anything or represent anything. They are just formal counters" (Searle, 1982, p. 4, emphasis in original). Insofar as the mind does not function like a computer, it is a mistake to continue to construct theories, research, and canons of theoretical evaluation on models based on high-speed formal counters.

A second, even broader, assumption underlying a disciplinary cult of celerity is the utilitarian assumption. Anderson (1978) explicitly links efficiency with the utilitarian assumption when he asserts that: "it is reasonable to assume that the human system processes information in a way to maximize the efficiency and optimality of its performance" (p. 273). The second portion of this analysis shows us, I believe, a discipline characterized by both a marked attraction to celerity and a reasoned skepticism toward it. On the one hand, psychological researchers have pointed out the dangers of overly rapid thought and action-particularly, the danger of inaccuracy of judgment. On the other hand, one can sense nearly universal acceptance of the utilitarian principle that inaccuracy is the necessary price to be paid for a speed that is ultimately desirable (i.e., "adaptive"). Despite the prima facie force of this assumption, the idea that speed/efficiency serves the needs of survival is challenged by the existence of a number of human phenomena which appear to serve no practical or survival purposes whatever: e.g., dreams, illusory beliefs, ritual, and art as a serious activity (cf. Langer, 1942). For this reason too it is a mistake to build our research, theories, and canons of theoretical evaluation upon quasi-Darwinian assumptions that yield models of grey men figuratively walking as fast as they can, looking at nothing but their shoes.

If it is the case that the high-speed computer analogy fails as an accurate description of a significant range of human thought and behavior, it is even clearer that the computer analogy fails as a prescription. A discipline or a culture which sets up cybernetic celerity as a positive standard will have little patience with the more halting unfolding of things human - be they as mundane as recall or as lofty as charac- 
ter, friendship, and intellectual or artistic creation. Such impatience is expressed in the following statement of an artificial intelligence researcher (cited in Turkle, 1984):

We forget things, learning is incredibly slow and difficult. We try to teach something to somebody twenty times, and they still don't get it. If you did that to a computer, you'd have to complain and throw it out. (p. 262)

To the extent that this way of thinking prevails in a discipline or a culture, individual human beings and their more dilatory activities are susceptible to devaluation. This sort of velocity-veneration overlooks the host of things in life which simply cannot be rushed, even if we wished to rush them - childbirth and the passing of the seasons being just two of these. In addition, it ignores the multitude of things in life which it is a crime to rush, if only because of the inexcusable loss of pleasure-being a child, simmering spaghetti sauce, traveling in Oregon, and making love being only a few of these. In short, the following criticism leveled against the criterion of economy in fiction (Broyard, 1981) applies more broadly to science and to society: "we may be purchasing formal economy at the price of moral and psychological stinting" (p. 31).

\section{CONCLUSIONS}

I am not a subscriber to the idea that psychology's assumptions and theories create an image of human nature which is then adopted by the person-on-the-street, thereby substantially altering human behavior (Gergen, 1972). I doubt that psychology as an academic discipline packs such a wallop in the "real world." Instead, I think it more likely that psychology - and science more generally - tends to mirror the values of the time and place in which it exists (Berger, 1963; Berger \& Luckmann, 1967; Kuhn, 1970). But to the extent that psychological theory and research reflect and fail to challenge values shared by the larger community, psychology's view of human nature is of more than academic interest. The primary aim of this analysis and critique has been to begin to reveal the manner in which psychological theory and research may be in this instance subverted by values prevalent in Western culture. Specifically, the aforementioned speed-driven phenomena observed by psychology, as well as the criterion of efficiency favored by some psychologists, reflect a veneration of cybernetic speed widespread in developed culture. Indeed, it appears that in some sense psychology, like Craig W., is bent on "showing us ways to save time we never knew we had."

In closing, it bears repeating that the undeniable virtues of the computer and of the speed and efficiency which it fosters should not blind us to the imperative for critical thought concerning the possible consequences of adopting the computer as a model for human thought and action. More generally, the proper response to technological advances which accelerate the tempo of human life and to scientific theories which enshrine celerity is neither abolition nor capitulation. Rather, it is through a critical accommodation with such advances that we are most apt to honor human psychology in all its languorous richness. Out of this kind of critical accommodation, we as individuals, as a society, and as a discipline may eventu- 
ally come to be able to say about our thought, our action, and our theory: "This will take some time" - and to say so without apology.

\section{REFERENCES}

Anderson, J.R. (1978). Arguments concerning representations for mental imagery. Psychological Review, 85, 249-277.

Anderson, J.R., \& Bower, G.H. (1973). Human associative memory. Washington, DG: Winston.

Andrews, F.M., \& Farris, G.F. (1976). Time pressure. In D.C. Pelz \& F.M. Andrews (Eds.), Scientists in organizations: Productive climates for research and development (pp. 367-383). Ann Arbor, MI: Institute for Social Research

Batson, C.D., Cochran, P.J., Biederman, M.F., Blosser, J.L., Ryan, M.J., \& Vogt, B. (1978). Failure to help when in a hurry: Callousness or conflict? Personality and Social Psychology Bulletin. 4, 97-101.

Bell, D. (1973). The coming of the post-industrial society. New York: Basic Books.

Bell, D. (1980). The winding passage: Essays and sociological journeys 1960-1980. New York: Basic Books.

Berger, P.L. (1963). Invitation to sociology: A humanistic perspective. New York: Anchor.

Berger, P.L., \& Luckmann, T. (1967). The social construction of reality: A treatise in the sociology of knowledge. New York: Doubleday.

Blanchard, K., \& Johnson, S. (1981). The one-minute manager. New York: Berkely Books.

Broyard, A. (1981, August 23). Wasteful economies. Newe York Times Book Review (p. 31).

Darley, J.M., \& Batson, C.D. (1973). From Jerusalem to Jeriocho: A study of situational and dispositional variables in helping behavior. Journal of Research in Personality, 27, 127-138.

Dennett, D. (1978). Brainstorms. Montgomery, VT: Bradford Books.

Dreyfus, H. (1979). What computers can't do: The limits of artificial intelligence. New York: Harper \& Row.

Fox Keller, E. (1983). A feeling for the orgamism: The life and werk of Barbara McClintock. New York: Freeman.

Gentner, D., \& Grudin, J. (1985). 'The evolution of mental metaphors in psychology: A 90-yeal retrospective. American Psychologist, 40, 181-192.

Gergen, K.J. (1973). Social psychology as history. Journal of Personality and Social Psychology, 26, $309-320$.

Hofstadter, D. (1979). Gödel, Escher, Bach: An eternal golden braid. New York: Basic Books.

Horkheimer, M. (1941/1978). The end of reason. In A. Arato \& E. Gebhardt (Eds.), The essential Frankfurt School reader. New York: Urizen Books.

Johnson, J.'T. (1986). The knowledge of what might have been: Affective and attributionat consequences of near outcomes. Personality and Social Psychology Bulletin, 12, 51-62.

Johnson, S. (1983a). The one-minute father. New York: William Morrow.

Johnson, S. (1983b). The one-minute mother. New York: William Morrow.

Jones, E.E., \& Davis, L. (1965). From acts to dispositions: The attribution process in person perception. In I. Berkowitz (Ed.), Advances in Experimental Social Psychology (Vol. 2). New York: Academic Press.

Juster, N. (1961). The phantom tollbooth. New York: Random House.

Kahneman, D., \& Tversky, A. (1972). Subjective probability: A judgment of representativeness. Cognitive Psychology, 3, 430-454.

Kahneman, D., \& Tversky, A. (1973). On the psychology of prediction. Psychological Review, 80, $237-251$.

Kahneman, D., \& Tversky, A. (1982a). The psychology of preferences. Scientific American, 246, $160-173$

Kahneman, D., \& Tversky, A. (1982b). The simulation heuristic. In D. Kahneman, P. Slovic, \& A. Tversky (Eds.), Judgment under uncertainty: Heuristics and biases. New York: Cambridge University Press.

Kelly, J.R., \& McGrath, J.E. (1985). Effects of time limits and task types on task performance and interaction of four-person groups. Journal of Personality and Social Psychology, 49, 395-407.

Kenny, D.A. (1979). Correlation and causality. New York: Wiley.

Kuhn, T. (1970). The structure of scientific revolutions (2nd ed.). University of Chicago Press. 
Landman, J.T. (1984). Regret and undoing: Retrospective assessment of hypothetical and real-life events. Unpublished doctoral dissertation, The University of Michigan.

Landman, J. (in press). Regret and elation following action and inaction: Affective responses to positive versus negative outcomes. Personality and Social Psychology Bulletin.

Langer, S. (1942). Philosophy in a new key: A study in the symbolism of reason, rite, and art. Cambridge, MA: Harvard University Press.

Linder, S.B. (1970). The harried leisure class. New York: Columbia University Press.

Luchins, A.S. (1942). Mechanization in problem solving. Psychological Monographs, 54, 95.

Mandler, G. (1981, September). What is cognitive psychology? What isn '? Paper presented at the American Psychological Association convention in Los Angeles, California.

Marcuse, H. (1964). One-dimensional man: Studies in the ideology of advanced industrial society. Boston: Beacon Press.

McGrath, J.E., Kelly, J.R., \& Machatka, D.E. (1984). The social psychology of time: Entrainment of behavior in social and organizational settings. In S. Oskamp (Ed.), Applied Social Psychology Annual, 5, 21-44.

Meeting the big U. (1981, September). Ann Arbor Observer, p. 10.

Mill, J.S. (1859/1952). On liberty. In Great Books of the Western World. Chicago: University of Chicago Press.

Moody, S. (1984a, July 1). The Valley: Part I. Ann Arbor News, p. A15.

Moody, S. (1984b, July 8). The Valley: Part II. Ann Arbor News, p. A14.

Nietzsche, F. (1874/1964). The use and abuse of history. In Thoughts out of season. (A. Collins, Trans.). New York: Russell and Russell.

Papert, S. (1980). Mindstorms: Children, computers and powerful ideas. New York: Basic Books.

Reich, R.B. (1983). The next American frontier. New York: Times Books.

Searle, J.R. (1982, April 29). The myth of the computer. Review of D.R. Hofstadter \& D.C. Dennett's The mind's I: Fantasies and reflections on self and soul. In New York Review of Books (Vol. 29, Pp. 3-6).

Simon, H. (1969). The Sciences of the Artificial. (2nd ed). Cambridge, MA: The Massachusetts Institute of Technology Press.

Taylor, S.E., \& Fiske, S.T. (1978). Salience, attention, and attribution: Top of the head phenomena. In L. Berkowitz (Ed.), Advances in Experimental Social Psychology (Vol. 11). New York: Academic Press.

Thagard, P. (1982, August). Programs, theories, and models. Paper presented at the 4th Annual Conference of the Cognitive Science Society, University of Michigan, Ann Arbor, Michigan.

Time. (1983, January 3). Cover.

Turkle, S. (1984). The second self: Computers and the human spirit. New York: Simon and Schuster.

Tversky, A., \& Kahneman, D. (1973). Availability: A heuristic for judging frequency and probability. Cognitive Psychology, 5, 207-232.

Weizenbaum, J. (1979). Computer power and human reason: From judgment to calculation. San Francisco: Freeman.

Winston, P. (1977). Artificial intelligence. Reading, MA: Addison-Wesley.

Yukl, G.A., Malone, M.P., Hayslip, B., \& Pamin, T.A. (1976). The effects of time pressure and issue settlement order on integrative bargaining. Sociometry, 39, 279-281. 